\title{
Desenvolvimento de mudas de aceroleira propagadas por estacas e sementes em solo compactado ${ }^{1}$
}

\author{
Development of West Indian Cherry plants development propagated \\ by cuttings or seeds in compacted soil \\ Ivan Bordin $^{1}$ Carmen Silvia Vieira Janeiro Neves ${ }^{3}$ \\ Mateus Carvalho Basílio de Azevedo ${ }^{4}$ Luiz Henrique Ilkiu Vidal $^{5}$
}

\section{RESUMO}

\begin{abstract}
O trabalho teve como objetivo avaliar o desenvolvimento da parte aérea e do sistema radicular de mudas de aceroleira (Malpighia emarginata D.C.) propagadas por sementes e por estacas, sob níveis de compactação subsuperficial de solo. Foram montados vasos com $200 \mathrm{~mm}$ de diâmetro e $285 \mathrm{~mm}$ de altura, divididos em três anéis sobrepostos de 100, 35 e $150 \mathrm{~mm}$. O solo do anel intermediário foi submetido a quatro níveis de densidade $\left(1,0 ; 1,21,4\right.$ e $\left.1,6 \mathrm{~kg} \mathrm{dm}^{-3}\right)$. O experimento foi conduzido com delineamento experimental de blocos ao acaso, num esquema fatorial de $2 \times 4$ (duas formas de propagação $e$ quatro densidades de solo), com cinco repetições. $O$ aumento da densidade do solo propiciou um maior desenvolvimento da parte aérea e raízes das mudas propagadas por estacas em relação às propagadas por sementes. Independente da forma de propagação utilizada, os níveis de densidade do solo avaliados não impediram a penetração das raízes de aceroleira.
\end{abstract}

Palavras-chave: Malpighia emarginata D.C., vasos, raiz, densidade do solo.

\section{ABSTRACT}

The objective of this research work was to evaluate West Indian Cherry (Malpighia emarginata D.C.)

\begin{abstract}
above-ground and root system development, in plants propagated by seeds and cuttings at different soil density levels $\left(1,0 ; 1,2 ; 1,4\right.$ and $\left.1,6 \mathrm{~kg} \mathrm{dm}^{-3}\right)$. The experiment was carried out in pots with $200 \mathrm{~mm}$ diameter and $285 \mathrm{~mm}$ height, divided in three rings with 100,35 and $150 \mathrm{~mm}$ height. The experimental design was totally randomized in a factorial arrangement $2 \times 4$ (two propagation forms and four soil densities) with five replications. The increase in soil density improved a higher above-ground parts and roots development in plants propagated by cuttings. Independent of the propagation method, the studied soil density levels did not prevent the root penetration.
\end{abstract}

Key words: Malpighia emarginata D.C, pots, root, soil density.

\section{INTRODUÇÃO}

A aceroleira (Malpiguia emarginata D.C.) pode ser propagada por via sexuada e assexuada. A propagação sexuada, por ser uma opção mais fácil e econômica, tem sido bastante empregada no Brasil, apesar de apresentar inconvenientes, como segregação das características da planta e frutos e desuniformidade na produção (GOMES et al., 1999). A

${ }^{1}$ Dissertação de Mestrado do primeiro autor apresentada ao Programa de Pós-graduação em Agronomia, Universidade Estadual de Londrina (UEL), Trabalho financiado pela Coordenação de Aperfeiçoamento de Pessoal de Nível Superior (CAPES).

${ }^{2}$ Engenheiro Agrônomo, Doutorando em Agronomia, UEL, Brasil. E-mail: ivanbordin@uel.br

${ }^{3}$ Engenheiro Agrônomo, Doutor, Professor Associado, Departamento de Agronomia, UEL, CP 6001, 86051-990, Londrina, PR, Brasil. Bolsista em Produtividade do Conselho Nacional de Desenvolvimento Científico e Tecnológico (CNPq). E-mail: csvjneve@uel.br. Autor para correspondência.

${ }^{4}$ Engenheiro Agrônomo, acadêmico do Programa de Pós-graduação em Agronomia, UEL, Bolsista CAPES. Departamento de Agronomia, UEL, Brasil.

${ }^{5}$ Engenheiro Agrônomo, Acadêmico do Programa de Pós-graduação em Agronomia, UEL. Professor Assistente, Departamento de Biologia, UEL, Brasil. 
propagação por estaquia assegura maior precocidade na produção, bem como mantém as características genéticas da planta multiplicada, garantindo a formação de pomares uniformes e com plantas selecionadas (TEIXEIRA \& AZEVEDO, 1995).

Apesar das vantagens do uso da estaquia, GONZAGA NETO \& SOARES (1994) relataram casos de tombamento de plantas propagadas por este método na região do sub-médio São Francisco, em conseqüência do vento e do sistema radicular adventício e superficial. Os autores destacaram a importância das mudas propagadas por enxertia em porta-enxertos oriundos de sementes que, além de aumentar a precocidade, proporcionam um sistema radicular mais vigoroso, o qual explora maior volume de solo, dando maior firmeza à planta. Ao avaliarem a distribuição do sistema radicular de aceroleiras com 4,5 anos de idade, propagadas por estaquia e por sementes, NEVES et al. (2002) constataram que, para as raízes menores que $0,5 \mathrm{~cm}$ de diâmetro, os resultados foram semelhantes, mas, para as raízes maiores de $0,5 \mathrm{~cm}$, o tratamento com plantas obtidas de semente apresentou maior densidade de raízes que o tratamento com plantas propagadas por estaquia.

A compactação do solo é um problema que tem sido observado em muitos pomares, em função do tráfego de implementos em solo com umidade inadequada e de práticas mecânicas de controle de invasoras. Plantas com raízes pivotantes mais grossas podem ser mais afetadas pela compactação do solo do que plantas com raízes fasciculadas mais finas, pois essas podem explorar canais já existentes no solo, deixadas por raízes que apodreceram ou por fissuras (WHITELEY \& DEXTER, 1982). Isto se dá, provavelmente, pelo fato de que as raízes finas têm diâmetros semelhantes aos diâmetros dos poros (SHIERLAW \& ALSTON, 1984). Entretanto, raízes de maior diâmetro apresentam maior resistência ao encurvamento quando penetram em solo compactado, o que é importante em solos deficientes em macroporos, onde as raízes necessitam deformar mais o solo do que explorar fissuras e poros (WHITELEY \& DEXTER, 1982).

Devido à escassez de dados referentes ao comportamento de árvores frutíferas propagadas por sementes ou por estacas em relação à compactação do solo, este trabalho teve como objetivo avaliar o desenvolvimento da parte aérea e do sistema radicular de mudas de aceroleira propagadas por estes métodos, em diferentes níveis de compactação subsuperficial do solo.

\section{MATERIAL E MÉTODOS}

O trabalho foi realizado no período de março a setembro de 2003, em casa de vegetação, na Universidade Estadual de Londrina-UEL, cujas coordenadas geográficas são: Latitude 232' Sul e Longitude $51^{\circ} 11$ Oeste, com $560 \mathrm{~m}$ de altitude. O solo utilizado é um Latossolo Vermelho distroférrico que foi coletado na camada superficial até a profundidade de $30 \mathrm{~cm}$. Os resultados das análises granulométrica e química (EMBRAPA, 1997) mostraram $815 \mathrm{~g} \mathrm{~kg}^{-1} \mathrm{de}$ argila, $170 \mathrm{~g} \mathrm{~kg}^{-1}$ de areia, $15 \mathrm{~g} \mathrm{~kg}^{-1}$ de silte; $2,7 \mathrm{~g} \mathrm{dm}^{-3}$ de matéria orgânica, 4,3 de $\mathrm{pH}$ em $\mathrm{CaCl}_{2}\left(0,01 \mathrm{~mol} \mathrm{~L}^{-1}\right)$, $0,9 \mathrm{mg} \mathrm{dm}^{-3}$ de P, $0,03 \mathrm{cmol} \mathrm{dm}^{-3} \mathrm{de} \mathrm{K}^{+}, 2,1 \mathrm{cmol}_{\mathrm{c}} \mathrm{dm}^{-3} \mathrm{de}$ $\mathrm{Ca}^{2+}, 1,0 \mathrm{cmol}_{\mathrm{c}} \mathrm{dm}^{-3}$ de $\mathrm{Mg}^{\mathrm{c}}$, 3,97 $\mathrm{cmol} \mathrm{dm}^{-3}$ de $\mathrm{H}^{+}+$ $\mathrm{Al}^{3+}, 0,02 \mathrm{cmol}_{\mathrm{c}} \mathrm{dm}^{-3} \mathrm{de} \mathrm{Al}^{3+}, 3,1 \mathrm{cmol} \mathrm{dm}^{\mathrm{c}}$ de soma de bases (SB), $7,1 \mathrm{cmol}_{\mathrm{c}} \mathrm{dm}^{-3}$ de capacidade de troca catiônica (CTC) e 44\% de saturação de bases (V\%).

Foram confeccionados vasos de $200 \mathrm{~mm}$ de diâmetro e $285 \mathrm{~mm}$ de altura, utilizando-se tubos de PVC divididos em três anéis sobrepostos de 100, 35 e $150 \mathrm{~mm}$. O material de solo utilizado no preenchimento dos vasos foi peneirado em malha de $10 \mathrm{~mm}$ e corrigido com calcário calcítico e adubo químico na formulação 4-14-8, elevando os níveis de nutrientes do solo para $50 \% \mathrm{Ca}^{2+}, 10 \% \mathrm{Mg}^{2+}$, 3\% $\mathrm{K}^{+}$e $97,8 \mathrm{mg} \mathrm{dm}^{-3}$ de $\mathrm{P}$, seguindo a recomendação de equilíbrio químico do solo (ALBRESCH, 1996).

$\mathrm{O}$ anel superior foi preenchido com solo solto, enquanto o anel intermediário recebeu quatro níveis de compactação (1,0; 1,20; 1,40 e 1,60kg dm-3). Para isso, o solo teve sua umidade padronizada a $0,30 \mathrm{~kg}$ $\mathrm{kg}^{-1}$ e foi compactado utilizando-se um cilindro de madeira com diâmetro ligeiramente inferior ao dos anéis, que recebeu pancadas de um bloco de concreto de $8 \mathrm{~kg}$, suspenso manualmente por uma haste de ferro. O número de pancadas foi o necessário para acomodar uma massa conhecida de solo em um anel de volume conhecido, proporcionando as densidades desejadas. $\mathrm{O}$ anel inferior foi preenchido com solo com a densidade padronizada de $1,0 \mathrm{~kg} \mathrm{dm}^{-3}$. Antes da montagem dos vasos, foi colocada uma fita adesiva na borda dos anéis compactados, dobrada para dentro formando uma aba perpendicular à parede interna do anel, com a finalidade de não permitir a passagem de raízes entre o solo e a parede do vaso.

Para determinação da resistência do solo à penetração, foi utilizado um penetrômetro de bolso, com cone de $30^{\circ}$ de ângulo de vértice e altura de $40 \mathrm{~mm}$, sendo avaliados quatro pontos em cada uma das cinco repetições, para cada nível de compactação. Determinou-se também a porosidade total, utilizando as densidades do solo e densidade das partículas 
(KIEHL, 1979), adotando-se o valor de $2,83 \mathrm{~kg} \mathrm{dm}^{-3} \mathrm{como}$ densidade das partículas para o solo estudado (NEVES, 1998) (Tabela 1). Para obtenção das mudas de aceroleira, foram utilizadas plantas matrizes da cultivar UEL 4 - Lígia com 10 anos de idade e bom estado fitossanitário, pertencentes ao pomar da Fazenda Escola da Universidade Estadual de Londrina. As mudas foram propagadas por sementes e estacas, respectivamente semeadas em canteiros de areia e estaqueadas em bandejas plásticas preenchidas com casca de arroz carbonizada, em casa de vegetação com 50\% de luminosidade e irrigação em regime intermitente durante 40 dias. Em função de um teste prévio para enraizamento de estacas de aceroleira, foi realizada a emersão da base das estacas em solução de 500 $\mathrm{mg} \mathrm{L}^{-1}$ de ácido indol-butírico, por 10 segundos. Foram utilizadas estacas com 12 a $15 \mathrm{~cm}$ de comprimento e três pares de folhas.

Para o transplante, as mudas foram selecionadas padronizando-se o comprimento das raízes para que não ultrapassassem $15 \mathrm{~cm}$, correspondendo à profundidade do anel superior, evitando-se assim o risco de transplantar mudas com raízes enoveladas. Após o plantio das mudas nos vasos, os mesmos foram pesados diariamente durante um período de 30 dias, obtendo-se, assim, a referência para manutenção da umidade (60\% da capacidade de campo) durante o experimento. As irrigações foram realizadas com intervalos de três dias pela superfície dos vasos.

Após seis meses, foram realizadas as avaliações de número de folhas, diâmetro do colo, altura da planta, área foliar (com Medidor Foliar Área Meter modelo 100) e matéria seca da parte aérea em estufa a $65^{\circ} \mathrm{C}$ por 48 horas. Para a separação das raízes do solo, cada anel foi lavado com jatos de água sobre peneira com malha de $1 \mathrm{~mm}$. As raízes foram submetidas à leitura ótica com scanner e analisadas pelo programa SIARCS 3.0 (CRESTANA

Tabela 1 - Porosidade total e resistência à penetração de um Latossolo Vermelho distroférrico submetido a quatro níveis de compactação em vasos.

\begin{tabular}{lccc}
\hline Densidade do solo & $\begin{array}{c}\text { Porosidade } \\
\text { Total }\end{array}$ & $\begin{array}{c}\text { Penetrometria } \\
\text { penetraçância à }\end{array}$ & Umidade \\
\hline $\mathrm{kg} \mathrm{dm}^{-3}$ & $\mathrm{dm}^{3} \mathrm{dm}^{-3}$ & $\mathrm{MPa}$ & $\mathrm{kg} \mathrm{kg}^{-1}$ \\
\hline 1,0 & 0,64 & 0,08 & 0,33 \\
1,2 & 0,57 & 0,51 & 0,32 \\
1,4 & 0,50 & 0,85 & 0,32 \\
1,6 & 0,43 & 2,22 & 0,30 \\
\hline
\end{tabular}

et al., 1994) para obtenção do comprimento e da área. O diâmetro médio das raízes foi obtido pelo método descrito por HALLMARK \& BARDER (1984) e a matéria seca das raízes por pesagem após serem secas em estufa a $65^{\circ} \mathrm{C}$ por 48 horas.

O delineamento experimental foi de blocos ao acaso, sendo os tratamentos arranjados em esquema fatorial $2 \times 4$ (duas formas de propagação e quatro níveis de compactação), com cinco repetições sendo cada vaso uma unidade experimental. Os resultados foram submetidos à análise de variância e complementada pelo teste de Tukey à $5 \%$ de probabilidade. A variável número de folhas foi transformada usando $\sqrt{x+0,5}$

\section{RESULTADOS E DISCUSSÃO}

Nas densidades 1,2 e $1,6 \mathrm{~kg} \mathrm{dm}^{-3}$, as aceroleiras propagadas por estaquia foram superiores às obtidas por sementes, em todas as variáveis referentes à parte aérea (Tabela 2). Na densidade de $1,4 \mathrm{~kg} \mathrm{dm}^{-3}$, somente o diâmetro do caule das plantas obtidas por estacas superou o das obtidas por sementes. A superioridade no desenvolvimento da parte aérea, apresentada pelas estacas em relação às sementes, pode estar relacionada aos maiores níveis de carboidratos presentes nos ramos que serviram como fonte de energia para auxiliar no desenvolvimento das mudas (HARTTMANN et al., 1990).

As aceroleiras propagadas por estaquia apresentaram aumento do número de folhas, diâmetro do caule, altura da planta, matéria seca e área foliar à medida que foi aumentado o nível de compactação do solo, enquanto as aceroleiras propagadas por sementes não apresentaram diferenças entre as densidades do solo para estas variáveis (Tabela 2). O incremento de variáveis referentes à parte aérea em virtude do aumento da compactação do solo também foi encontrado por MÜLLER et al. (2001), ao trabalharem com tremoço branco. Em contrapartida, a diminuição do desenvolvimento da parte aérea com a compactação do solo foi evidenciada por ALVARENGA et al. (1996) ao trabalharem com o feijão-de-porco e feijão-bravodo-ceará. As respostas da parte aérea das plantas à compactação do solo são controversas. Relacionase a diminuição do seu desenvolvimento ao aumento dos níveis de compactação do solo, devido provavelmente à deficiência de água e nutrientes, assim numa condição de vasos, onde o fornecimento de água e nutrientes não são limitantes, seus efeitos podem não ser os esperados (SILVA \& ROSOLEM, 2001). 
Tabela 2 - Variáveis da parte aérea de mudas de aceroleira propagadas por estacas e sementes e submetidas a diferentes densidades do solo.

\begin{tabular}{|c|c|c|c|c|c|}
\hline \multirow{2}{*}{ Propagação } & \multicolumn{5}{|c|}{ Densidade do solo $\left(\mathrm{kg} \mathrm{dm}^{-3}\right)$} \\
\hline & 1,0 & 1,2 & 1,4 & 1,6 & Média \\
\hline \multicolumn{6}{|l|}{ Número de folhas } \\
\hline Estaca & $17,2 \mathrm{Ab}^{*}$ & 42,0 Aab & $23,4 \mathrm{Ab}$ & 58,8 Аа & 35,3 \\
\hline Semente & $17,4 \mathrm{Aa}$ & $15,4 \mathrm{Ba}$ & $17,6 \mathrm{Aa}$ & $10,8 \mathrm{Ba}$ & 15,3 \\
\hline Média & 17,3 & 28,7 & 20,5 & 34,8 & \\
\hline CV (\%) & 31,2 & & & & \\
\hline \multicolumn{6}{|c|}{ Diâmetro do caule $(\mathrm{cm})$} \\
\hline Estaca & $0,38 \mathrm{Ab}$ & 0,53 Аа & 0,40 Aab & 0,45 Aab & 0,44 \\
\hline Semente & 0,28 Аа & $0,27 \mathrm{Ba}$ & 0,22 Ba & 0,18 Ba & 0,22 \\
\hline Média & 0,33 & 0,40 & 0,31 & 0,32 & \\
\hline CV (\%) & & & 22,0 & & \\
\hline \multicolumn{6}{|c|}{ Altura da planta (cm) } \\
\hline Estaca & $10,9 \mathrm{Ab}$ & $24,8 \mathrm{Ab}$ & $15,4 \mathrm{~A} \mathrm{~b}$ & 50,3 Аа & 25,4 \\
\hline Semente & 9,2 Аа & 9,9 Ba & 8,8 Аа & $6,4 \mathrm{Ba}$ & 8,6 \\
\hline Média & 10,0 & 17,4 & 12,1 & 28,4 & \\
\hline CV (\%) & 57,2 & & & & \\
\hline \multicolumn{6}{|c|}{ Matéria seca da parte aérea (g) } \\
\hline Estaca & $0,98 \mathrm{Ab}$ & 4,05 Aab & $1,94 \mathrm{Ab}$ & 6,62 Аа & 3,40 \\
\hline Semente & 0,42 Аа & 0,36 Ba & 0,36 Аа & 0,19 Ва & 0,33 \\
\hline Média & 0,70 & 2,21 & 1,15 & 3,41 & \\
\hline CV (\%) & & 102,7 & & & \\
\hline \multicolumn{6}{|c|}{ Área foliar $\left(\mathrm{cm}^{2}\right)$} \\
\hline Estaca & $21,18 \mathrm{Ac}$ & 83,44 Aab & 37,38 Abc & $135,99 \mathrm{~A} \mathrm{a}$ & 69,50 \\
\hline Semente & 16,96 Аа & $16,07 \mathrm{Ba}$ & 15,67 Аа & 8,83 Ba & 14,38 \\
\hline Média & 19,07 & 26,53 & 49,76 & 72,41 & \\
\hline CV (\%) & 77,5 & & & & \\
\hline
\end{tabular}

*Médias seguidas da mesma letra maiúscula na coluna e minúscula na linha não diferem significativamente pelo teste de Tukey a 5\%.

Quanto ao desenvolvimento do sistema radicular no anel acima da camada compactada (Tabela 3), a propagação por estaquia foi superior à realizada com sementes em todas as densidades estudadas para a área radicular. Para a matéria seca e diâmetro radicular, somente na densidade de $1,0 \mathrm{~kg} \mathrm{dm}^{-3}$ não houve diferença entre as formas de propagação, enquanto nas outras densidades a propagação por estaquia também foi superior. Em relação às densidades do solo, a matéria seca, a área e o diâmetro das raízes das aceroleiras propagadas por estaquia foram superiores nas densidades $1,6 \mathrm{~kg} \mathrm{dm}^{-3} \mathrm{e} 1,2 \mathrm{~kg} \mathrm{dm}^{-3}$ em relação às demais densidades, enquanto as propagadas por sementes não foram influenciadas pela densidade do solo.

Observa-se que houve acúmulo das raízes na camada superior à camada compactada (Tabela 3) concordando com os resultados encontrados por ROSOLEM et al. (1994) em trabalho realizado em vaso com a cultura da soja. Isso evidencia a capacidade das mudas de acerola de compensar a redução do desenvolvimento radicular das camadas compactadas pelo crescimento das raízes em locais de menor resistência à penetração.

O comprimento das raízes não foi afetado nem pelo tipo de propagação e nem pelas diferentes densidades do solo (Tabela 3), concordando com o observado em plantas de cobertura verde submetidas à compactação do solo (SILVA \& ROSOLEM, 2001; MÜLLER et al., 2001).

Para o desenvolvimento do sistema radicular na camada compactada, não se constatou interação entre as formas de propagação e as densidades do solo. As plantas propagadas por estacas foram superiores às propagadas por sementes para matéria seca e diâmetro, não se diferenciando quanto à área e comprimento das raízes (Tabela 4).

Ciência Rural, v.35, n.3, mai-jun, 2005. 
Tabela 3 - Variáveis das raízes contidas nos anéis acima da camada compactada de mudas de aceroleira propagadas por estacas e sementes e submetidas a diferentes densidades do solo.

\begin{tabular}{|c|c|c|c|c|c|}
\hline \multirow{2}{*}{ Propagação } & \multicolumn{5}{|c|}{ Densidade do solo $\left(\mathrm{kg} \mathrm{dm}^{-3}\right)$} \\
\hline & 1,0 & 1,2 & 1,4 & 1,6 & Média \\
\hline \multicolumn{6}{|c|}{ Matéria seca de raízes (g) } \\
\hline Estaca & $0,34 \mathrm{Ab}^{*}$ & 0,70 Aab & 0,59 Ab & $1,04 \mathrm{Aa}$ & 0,68 \\
\hline Semente & $0,17 \mathrm{Aa}$ & 0,17 Ba & 0,21 Ba & 0,11 Ba & 0,16 \\
\hline Média & 0,26 & 0,43 & 0,40 & 0,57 & \\
\hline CV (\%) & & & 53,0 & & \\
\hline \multicolumn{6}{|c|}{ Área de raízes $\left(\mathrm{cm}^{2}\right)$} \\
\hline Estaca & $6,94 \mathrm{Ab}$ & 11,88 Aab & $11,47 \mathrm{Ab}$ & $16,94 \mathrm{Aa}$ & 11,81 \\
\hline Semente & 2,80 Ba & 2,50 Ba & 3,25 Ba & 2,80 Ba & 2,80 \\
\hline Média & 4,87 & 7,19 & 7,36 & 9,80 & \\
\hline CV (\%) & & & 43,8 & & \\
\hline \multicolumn{6}{|c|}{ Diâmetro de raízes (cm) } \\
\hline Estaca & $0,25 \mathrm{Ac}$ & 0,38 Aab & 0,33 Abc & $0,44 \mathrm{Aa}$ & 0,35 \\
\hline Semente & $0,18 \mathrm{Aa}$ & $0,18 \mathrm{Ba}$ & $0,20 \mathrm{Ba}$ & $0,04 \mathrm{Ba}$ & 0,17 \\
\hline Média & 0,22 & 0,28 & 0,27 & 0,29 & \\
\hline $\mathrm{CV}(\%)$ & & & 23,5 & & \\
\hline \multicolumn{6}{|c|}{ Comprimento de raízes (cm) } \\
\hline Estaca & 725,51 & 742,58 & 682,30 & 1019,45 & 792,46 A \\
\hline Semente & 167,53 & 151,74 & 213,32 & 152,33 & $171,23 \mathrm{~A}$ \\
\hline Média & 446,52 a & 447,16 a & $447,81 \mathrm{a}$ & 585,88 a & \\
\hline CV (\%) & & & 46,4 & & \\
\hline
\end{tabular}

*Médias seguidas da mesma letra maiúscula na coluna e minúscula na linha não diferem significativamente pelo teste de Tukey a 5\%

Tabela 4 - Variáveis das raízes contidas nos anéis da camada compactada e abaixo da camada compactada de mudas de aceroleira propagadas por estacas e sementes e submetidas a diferentes densidades do solo.

\begin{tabular}{|c|c|c|c|c|}
\hline Fatores & Massa seca de raízes (g) & Área de raízes (cm) & Comprimento de raízes (cm) & Diâmetro de raízes $(\mathrm{cm})$ \\
\hline \multicolumn{5}{|c|}{ Camada compactada } \\
\hline \multicolumn{5}{|c|}{ Propagação } \\
\hline Estaca & $0,02 \mathrm{~A}^{*}$ & $0,66 \mathrm{~A}$ & $40,55 \mathrm{~A}$ & $0,06 \mathrm{~A}$ \\
\hline Semente & 0,01 B & $0,77 \mathrm{~A}$ & $45,58 \mathrm{~A}$ & $0,04 \mathrm{~B}$ \\
\hline \multicolumn{5}{|c|}{ Densidade do solo $\left(\mathrm{kg} \mathrm{dm}^{-3}\right)$} \\
\hline 1,0 & $0,02 \mathrm{~A}$ & $0,73 \mathrm{~A}$ & $43,88 \mathrm{~A}$ & $0,05 \mathrm{~A}$ \\
\hline 1,2 & $0,02 \mathrm{~A}$ & $0,47 \mathrm{~A}$ & $28,45 \mathrm{~A}$ & $0,06 \mathrm{~A}$ \\
\hline 1,4 & $0,01 \mathrm{~A}$ & $1,00 \mathrm{~A}$ & $59,16 \mathrm{~A}$ & $0,05 \mathrm{~A}$ \\
\hline$\underline{1,6}$ & $0,02 \mathrm{~A}$ & $0,66 \mathrm{~A}$ & $40,78 \mathrm{~A}$ & $0,06 \mathrm{~A}$ \\
\hline $\mathrm{CV} \%$ & 98,5 & 78 & 78,5 & 48,6 \\
\hline \multicolumn{5}{|c|}{ Camada inferior à camada compactada } \\
\hline \multicolumn{5}{|c|}{ Propagação } \\
\hline Estaca & $0,06 \mathrm{~A}$ & $3,44 \mathrm{~A}$ & 202,92 A & $0,08 \mathrm{~A}$ \\
\hline Semente & 0,03 A & 3,30 A & 196,74 A & 0,06 B \\
\hline \multicolumn{5}{|c|}{ Densidade do solo $\left(\mathrm{kg} \mathrm{dm}^{-3}\right)$} \\
\hline 1,0 & $0,06 \mathrm{AB}$ & $4,30 \mathrm{AB}$ & $250,99 \mathrm{AB}$ & $0,09 \mathrm{AB}$ \\
\hline 1,2 & $0,10 \mathrm{~A}$ & 5,98 A & $352,27 \mathrm{~A}$ & $0,11 \mathrm{~A}$ \\
\hline 1,4 & $0,02 \mathrm{~B}$ & $2,48 \mathrm{AB}$ & $149,07 \mathrm{AB}$ & $0,04 \mathrm{~B}$ \\
\hline 1,6 & $0,02 \mathrm{~B}$ & $0,78 \mathrm{~B}$ & $47,02 \mathrm{~B}$ & $0,03 \mathrm{~B}$ \\
\hline $\mathrm{CV} \%$ & 130,6 & 101,0 & 98,4 & 73,8 \\
\hline
\end{tabular}

*Médias seguidas da mesma letra na coluna não diferem significativamente pelo teste de Tukey a 5\%.

Ciência Rural, v.35, n.3, mai-jun, 2005. 
Tanto as aceroleiras propagadas por estacas, como as propagadas por sementes conseguiram penetrar suas raízes no solo submetido aos níveis de compactação. Isto ocorreu, provavelmente, porque as estacas com sistema radicular com matéria seca e diâmetro maior, utilizaram a pressão radicular para superar a camada de impedimento (WHITELEY \& DEXTER, 1982), enquanto as aceroleiras propagadas por sementes, com matéria seca e diâmetro menor, exploraram melhor os poucos poros das camadas compactadas para superá-las, evidenciando uma tendência de uniformidade de reação do sistema radicular dessas formas de propagação no decorrer do tempo.

Foi constatado um aumento gradativo da resistência à penetração do solo até a densidade de $1,4 \mathrm{~kg} \mathrm{dm}{ }^{-3}$, chegando a $2,2 \mathrm{Mpa}$ na camada mais compactada (TABELA 1). Em trabalhos semelhantes, encontra-se restrição total ao desenvolvimento radicular de plantas de milho entre 1,4 a 2,0MPa (SILVA et al., 2002; FOLONI et al., 2003) o que evidencia a capacidade de desenvolvimento do sistema radicular da aceroleira em camadas compactadas de solo, independentemente do método de propagação utilizado.

Não houve diferenças para matéria seca, área, comprimento e diâmetro das raízes em relação às densidades estudadas na camada compactada (Tabela 4). Entretanto, FOLONI et al. (2003) constataram que o comprimento e a matéria seca radicular do milho foram diminuídos com o aumento da compactação. Em contrapartida, ALVARENGA et al. (1996) relatam que existem plantas que se adaptam melhor a solos compactados, não alterando seu desenvolvimento, como no caso do mata-pasto, que é uma leguminosa muito comum em pastagens degradadas.

Não foi verificada interação entre as formas de propagação e as densidades do solo no desenvolvimento do sistema radicular no anel abaixo da camada compactada (Tabela 4). Nessa camada, as plantas propagadas por estacas foram superiores às propagadas por sementes somente para o diâmetro, não havendo diferenças para a matéria seca, área e comprimento das raízes. Em relação às densidades, todas as variáveis estudadas apresentaram diminuição à medida que aumentava o nível de compactação do solo. O menor desenvolvimento das raízes na camada inferior à camada compactada em relação ao aumento da compactação do solo pode ser atribuído ao fato de as raízes não conseguirem se recuperar do estresse ao qual foram submetidas, gastando maior quantidade de fotoassimilados (MASLE \& FARQUHAR, 1988).

\section{CONCLUSÕES}

O aumento da densidade do solo propicia um maior desenvolvimento da parte aérea e raízes das mudas propagadas por estacas em relação às propagadas por sementes. Os níveis de densidade do solo avaliados não impedem a penetração das raízes de mudas de aceroleira propagadas por estacas ou por sementes.

\section{REFERÊNCIAS BIBLIOGRÁFICAS}

ALBRESCH, W.A. The Albresch paper - foundation concepts. 3.ed. Louisiana : Agres USA, 1996. V.1. 515p.

ALVARENGA, R.C. et al. Crescimento de raízes de leguminosas em camadas de solo compactadas artificialmente. Revista Brasileira de Ciência do Solo, Campinas, v.20, n.2, p.319326, 1996.

CRESTANA, A. et al. Avaliação da distribuição de raízes no solo auxiliada por processamento de imagens. Revista Brasileira de Ciência do Solo, Viçosa, v.18, n.3, p.365371, 1994.

EMBRAPA-EMPRESA BRASILEIRA DE PESQUISA AGROPECUÁRIA. Manual de métodos de análise de solos. 2.ed. Rio de Janeiro : EMBRAPA Solos, 1997. 212p.

FOLONI, J.S.S. et al. Efeito da compactação do solo no desenvolvimento aéreo e radicular de cultivares de milho. Pesquisa Agropecuária Brasileira, Brasília, v.38, n.8, p.947-953, 2003.

GOMES. J.E. et al. Variabilidade fenotípica em genótipos de acerola. Pesquisa Agropecuária Brasileira, Brasília, v.35, n.11, p.2205-2211, 1999.

GONZAGA NETO, L.; SOARES, J.M. Acerola para exportação: aspectos técnicos da produção. Brasília : EMBRAPA-SPI, 1994. 43p. (Série Publicações Técnicas FRUPEX, 10).

HALLMARK, W.B.; BARBER, S.A. Root growth and morphology, nutrient uptake and nutrient status of early growth of soybeans as affected by soil P and K. Agronomy Journal, Madison, v.76, n.2, p.209-212, mar-apr, 1984.

HARTTMANN, H.T. et al. Plant propagation: principles and practices. 5.ed. New Jersey : Prentice Hall, 1990. 647p.

KIEHL, E.J. Manual de edafologia: relações solo-planta. São Paulo : Ceres, 1979. 264p.

MASLE, J.; FAQUHAR, G.D. Effects of soil strenght on the relation of warer-use efficiency and growth to carbon isotope discrimination in wheat seedlings. Plant Physiology, Massachusetts, v.86, n.1, p.32-38, 1988.

MÜLLER, M.M.L. et al. Influência da compactação do solo em subsuperfície sobre o crescimento aéreo e radicular de plantas de adubação verde de inverno. Revista Brasileira de Ciência do Solo, Viçosa, v.25, n.3, p.531538, 2001. 
NEVES, C.S.V.J. et al. Sistema radicular de aceroleiras propagadas por sementes e por estacas no Paraná. In: CONGRESSO BRASILEIRO DE FRUTICULTURA, 17., 2002, Belém. Anais... Belém : Sociedade Brasileira de fruticultura, 2002. CD-ROM.

NEVES, C.S.V.J. Influência de sistemas de manejo em características de tangerina 'Poncã' sobre limão 'Cravo' e de um Latossolo Roxo. 1998. 158f. Tese (Doutorado em Solos e Nutrição de Plantas) - Curso de Pós-graduação em Agronomia, Escola Superior de Agricultura Luiz de Queiroz, Universidade de São Paulo.

ROSOLEM, C.A. et al. Sistema radicular e nutrição da soja em função da compactação do solo. Bragantia, Campinas, v.53 n.2, p.259-266, 1994.

SHIERLAW, J.; ALSTON, A.M. Effects of soil compaction on root growth and uptake of phosphorus. Plant and Soil, Hague, v.77, n.1, p.15-28, 1984.
SILVA, A. et al. Intervalo hídrico ótimo. In: MORAES, M. H. et al. Qualidade física do solo: métodos de estudosistemas de preparo e manejo do solo. Jaboticabal : FUNEP, 2002. p.1-18.

SILVA, H.R.; ROSOLEM, C.A. Crescimento radicular de espécies utilizadas como cobertura decorrente da compactação do solo. Revista Brasileira de Ciência do Solo, Viçosa, v.25, n.2, p.253-260, 2001.

TEIXEIRA, A.H.C.; AZEVEDO, P.V. Índices-limite do clima para o cultivo da acerola. Pesquisa Agropecuária Brasileira, Brasília, v.30, n.12, p.1403-1410, 1995.

WHITELEY, G.M.; DEXTER, A.R. Root development and growht of oilseed, wheat and pea crops on tilled and non-tilled soil. Soil \& Tillage Research, Amsterdam, v.2, n.4, p.379393, 1982. 